\title{
A 10 -year survey on prevalence and occurrence rate of multi-drug resistant Mycobacterium tuberculosis in Latin American and Mediterranean Families: A Systematic review and meta-analysis
}

Samaneh Rouhi ${ }^{1,2}$, Daem Roshani ${ }^{3}$, Pegah Shakib $^{1,2}$, Fatemeh AhangarKani ${ }^{4}$, Rashid Ramazanzadeh $^{2,5^{*}}$

1. Student Research Committee, Kurdistan University of Medical Sciences, Sanandaj, Iran

2. Cellular and Molecular Research Center, Kurdistan University of Medical Sciences, Sanandaj, Iran

3. Social Determinants of Health Research Center, Kurdistan University of Medical Sciences, Sanandaj, Iran

4. Antimicrobial Resistance Research Center, Student Research Committee, Mazandaran University of Medical Sciences, Sari, Iran

5. Department of Microbiology, Faculty of Medicine, Kurdistan University of Medical Sciences, Sanandaj, Iran

*Corresponding author:Tel: +98 9143104424Fax: +98 8716664674

Address: Cellular \& Molecular Research Center and Microbiology Department, Faculty of Medicine, Kurdistan University of Medical Science, Pasdaran Street, Post cod. 66177-13446, Sanandaj, Iran

E-mail:atrop_t51@yahoo.com

Received; 2017/07/6 revised; 2017/09/1 accepted; 2017/11/13

\section{Abstract}

Introduction: Latin American and Mediterranean (LAM) is a family of Mycobacterium tuberculosis (M. tuberculosis). Drug resistant in M. tuberculosis LAM family is a major problem in the world population. Our objective of this study was to determine the prevalence of $M$. tuberculosis LAM family with multi-drug resistant (MDR) in the worldwide by a metaanalysis and systematic review.

Materials and methods: Data sources of this study were 68 original articles (2001-2012) which were published in different databases. Research articles with full text in English were selected. Review articles, congress abstracts, studies that were reported in languages other than English and also studies that were not available for us in abstract or full text were excluded. Data that were obtained from prevalence and occurrence rate of MDR M. tuberculosis LAM family were analyzed using meta-analysis random effects models with software package Meta $\mathrm{R}$, Version $2.13(\mathrm{P}<0.10)$.

Results: During 10 years, lowest rate of prevalence was observed in 2010 and 2006 (95\% CI: $5.91 \%-6.95 \%$ ) and highest prevalence rate was in 2006 (95\% CI: 17.48\%- 24.05\%). prevalence of MDR- M. tuberculosis analysis showed positive MDR between them (95\% CI: $10.30 \%$ $11.23 \%$ ). Prevalence for negative MDR was $9.22 \%$ (95\% CI: $8.3 \%-10.2 \%$ ).

Conclusion: Our study showed that M. tuberculosis LAM family is prevalent in Europian countries. LAM sub lineage was a major focus of studies that carried out in different countries. The proper technique for prevention of transmission of $M$. tuberculosis is necessary.

Keywords: Prevalence, Mycobacterium tuberculosis, Latin American and Mediterranean Family, Multi-Drug Resistant

Copyright (C) 2018 Journal of Basic Research in Medical Science. This is an open access article distributed under the terms of the Creative Commons Attribution 4.0 International License (https://creativecommons.org/licenses/by/4.0/) which permits copy and redistribute the material, in any medium or format, provided the original work is properly cited. 


\section{Introduction}

Tuberculosis (TB) is a bacterial infectious disease caused by Mycobacterium tuberculosis (M. tuberculosis).It is still an important cause of morbidity and mortality $(1,2)$. TB can be seen in various forms including pulmonary and extra pulmonary (3). Epidemiological estimates in 2011 showed 1.4 million deaths and 8.7 million new cases of TB in world (4). For example, reports in Moscow showed $M$. tuberculosis morbidity about 50 cases per 100,000 people in 2008 (5). The best way to treat $\mathrm{TB}$ is antibiotic treatment. Antibiotics used to treat including first-line drugs (isoniazid, rifampin, ethambutol, and streptomycin) and second-line drugs (aminoglycosides, kanamycin, amikacin, and fluoroquinolones) (6-9). The dramatic rise and the increasing emergence of drugresistant $M$. tuberculosis isolates are causes for concern attention to this disease (10-13). Many reports presented multi-drug resistance (MDR) -M. tuberculosis that resistant to at least both isoniazid and rifampin. This problem cause TB, increasing treatment period, rising health care costs, and mortality rates (14-16). Also studies showed that transmission of different $M$. tuberculosis families are associated with drug resistance in worldwide populations. The main genotype families of $M$. tuberculosis are beijing, haarlem, east-african-indian(EAI), latinamerican and mediterranean(LAM), U and T strains $(9,10)$. LAM is one of $M$. tuberculosis phylogenetic family and its name is derived from the geographical area which was isolated. LAM sub lineage was a major focus of studies in different area of Americas, Europe, Africa and Russia (11). Different studies reported MDR- $M$. tuberculosis among $M$. tuberculosis LAM family; Ignatova et al. in Russia reported that members of the LAM families were MDR in the populations that were studied (17). In other study,Valcheva et al. in Bulgaria showed that a higher MDR rate among LAM families (18). Dymova et al. in Russian using variable number tandem repeat (VNTR) and restriction fragment length polymorphism (RFLP) - insertion sequence (IS) 6110-typing showed that, in M. tuberculosisisolates that were isolated from 98 TB patients, 75 different genetic profiles were detected. Also an association was observed between the LAM strain family and MDR (19, 20). Therefore, control and MDR patient's detection are required for TB treatment. The aim of our study is a survey on prevalence and occurrence rate of $M$. tuberculosis LAM family with MDR during 10 years among different countries, based on a systematic review and meta-analysis. It may be helpful in prevention and control of M. tuberculosis LAM family with MDR in the world population.

\section{Materials and methods}

Data Sources: For prevalence determination of $M$. tuberculosis LAM family with MDR and occurrence rate in the worldwide population, literature databases (PubMed, Science Direct, Google Scholar, ISI Web of Science, and Biological Abstracts) and original articles were considered between 2001-2012 years in English language. Key words for search in databases were M. tuberculosis, TB, LAM family and MDR.

Study Selection: Process for selecting the studies: the data includes number of cases, websites, author, study place, year of the research, sample size, and prevalence of LAM and MDR association. Inclusion criteria were: (1) research articles with full text, (2) articles with abstract in English. Excluded studies were: (1) review articles, (2) congress abstracts, (3) studies that reported in languages other than English, (4) studies that were not available for us in abstract or full text, (5) studies that their sampling location was uncertain, (6) studies that locations of sampling was performed at the same time, and (7) studies that their data were not clear (see Flowchart 1). 
Data Extraction: In our study 106 articles were selected. The variance of prevalence was computed using binomial distribution and meta-analysis with the random effect model which was applied to combine the prevalence among the studies. There was sensitivity and heterogeneity among the studies. Inconsistency ( $\left.\mathrm{I}^{2}\right), \quad(95 \%$ confidence interval, $\mathrm{CI}$ ) and Cochran $\mathrm{Q}$ $(\mathrm{P}<0.10)$ statistical tests were used to check out this heterogeneity. Meta R Version 2.13 software package for Meta-analysis was applied.

\section{Results}

68 original articles (published 2001 to 2012) were reviewed from 106 original articles. The total population that was obtained from articles in this meta-analysis was 25501 (Table 1). According to the countries and the years, the highest prevalence rate of $M$. tuberculosis LAM family was in Venezuela in 2006 and the lowest rate was in Pakistan and Iran in 2010 and 2006 (both $0.2 \%$ ), respectively Also patients with MDR -TB were observed in these studies (Table 1)

Prevalence of $M$. tuberculosis LAM family in Worldwide Population Based on Years of Study: The data for 10 groups were analyzed during 2001-2012. The lowest rate of prevalence was observed in 2010 and 2006 [6.42\% (95\% CI: 5.91\%$6.95 \%)]$. Highest prevalence rate was in 2012 [20.62\% (95\% CI: $17.48 \%-24.05 \%$ )]. In this heterogeneity, $\mathrm{I}^{2}=97.7$, Chi-squared $=383.86$, degrees of freedom $(\mathrm{df})=9$ with $\mathrm{P}<0.00$ and between-study variance (tausquared) $=0.01$ with $\mathrm{P}=0.00$ were obtained. Also, publication bias result is presented in Figure 1 (also, Table 2).

Citation identified though PubMed (57), Science Direct

(10), Google Scholar (5), ISI (29), and Biological Abstracts

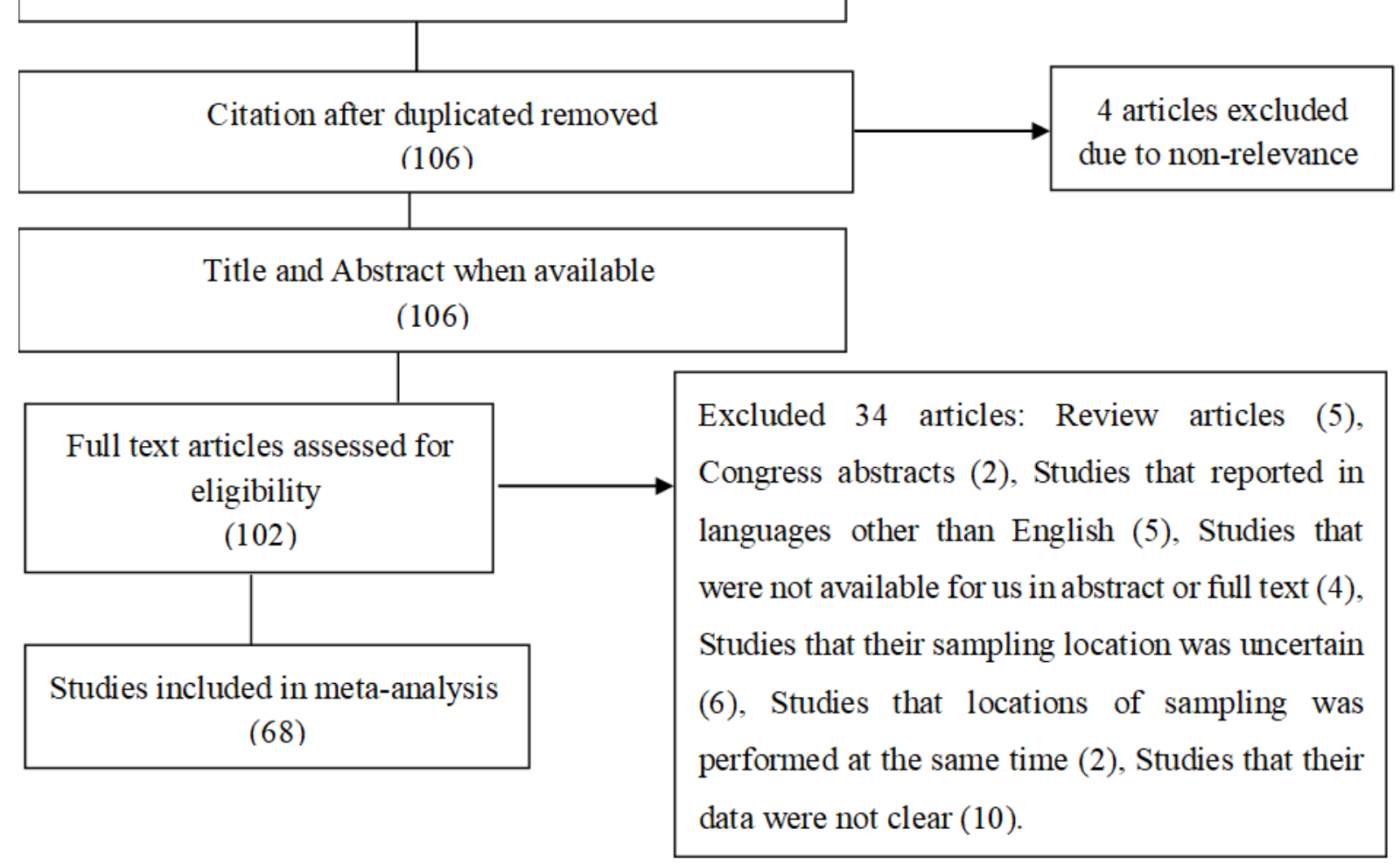

Flowchart 1. Flow diagram for study selection. 
Table 1. Data that were extracted from published documents about country, year, and prevalence of $M$. tuberculosis Latin American and Mediterranean (LAM) family and multi-drug resistant (MDR).

\begin{tabular}{|c|c|c|c|c|c|c|c|c|c|}
\hline References & Country & Year & Prevalence & MDR & References & Country & Year & Prevalence & MDR \\
\hline (1) & Georgia & 2010 & $18 \%$ & Yes & (18) & Tanzania & 2006 & $22 \%$ & - \\
\hline (3) & Ghana & 2011 & $1.54 \%$ & - & (36) & Turkey & 2007 & $28.60 \%$ & No \\
\hline (5) & Guinea & 2011 & $18.12 \%$ & - & (37) & Russia & 2007 & $46 \%$ & No \\
\hline (7) & Brazil & 2011 & $10.30 \%$ & - & (38) & UK & 2010 & $0.80 \%$ & Yes \\
\hline (9) & Colombia & 2011 & $49.34 \%$ & - & (39) & Italy & 2007 & $11.20 \%$ & - \\
\hline (11) & Mozambique & 2010 & $37 \%$ & - & (40) & Brazil & 2011 & $55.3 \%$ & - \\
\hline (13) & Honduras & 2010 & $55 \%$ & - & (41) & Turkey & 2007 & $7.90 \%$ & - \\
\hline (15) & Ireland & 2010 & $4.10 \%$ & - & (42) & Malawi & 2010 & $51.70 \%$ & - \\
\hline (17) & Malawi & 2010 & $44.30 \%$ & - & (43) & Turkey & 2007 & $29 \%$ & - \\
\hline (19) & Taiwan & 2010 & $2.56 \%$ & Yes & (44) & Italy & 2009 & $12.80 \%$ & - \\
\hline (20) & Guadeloupe & 2006 & $19.70 \%$ & - & (45) & Paraguay & 2007 & $52.3 \%$ & - \\
\hline (21) & Poland & 2010 & $13.00 \%$ & Yes & (46) & Saudi Arabia & 2007 & $7.2 \%$ & - \\
\hline (22) & Iran & 2006 & $0.2 \%$ & No & (47) & China & 2011 & $1.1 \%$ & Yes \\
\hline (23) & China & 2010 & $0.80 \%$ & Yes & (48) & Venezuela & 2006 & $74 \%$ & - \\
\hline (24) & Indonesia & 2009 & $6.3 \%$ & - & (49) & Colombia & 2011 & $49.34 \%$ & - \\
\hline (25) & South Africa & 2010 & $28.80 \%$ & - & (50) & Italy & 2005 & $5.2 \%$ & - \\
\hline (26) & Myanmar & 2009 & $4.50 \%$ & Yes & (51) & Taiwan & 2008 & $5.80 \%$ & - \\
\hline (27) & Italy & 2010 & $12.80 \%$ & - & (52) & Russia & 2004 & $23.8 \%$ & - \\
\hline (28) & Turkey & 2009 & $15 \%$ & Yes & (53) & Portugal & 2007 & $51 \%$ & - \\
\hline (29) & Russia & 2009 & $17.8 \%$ & Yes & (54) & Russia & 2004 & $49.6 \%$ & - \\
\hline (30) & South Africa & 2000 & $29.50 \%$ & No & (55) & Taiwan & 2008 & $3.80 \%$ & - \\
\hline (31) & Venezuela & 2009 & $53 \%$ & Yes & (56) & Sweden & 2004 & $8 \%$ & No \\
\hline (32) & Japan & 2005 & $2 \%$ & No & (57) & Madagascar & 2005 & $6 \%$ & - \\
\hline (33) & sough & 2008 & $29.20 \%$ & No & (58) & Turkey & 2012 & $5.30 \%$ & Yes \\
\hline (34) & Trinidad & 2009 & $11.40 \%$ & - & (59) & Sudan & 2011 & $2.60 \%$ & - \\
\hline (35) & Sierra Leone & 2008 & $15.5 \%$ & Yes & (60) & Iran & 2009 & $0.45 \%$ & Yes \\
\hline (2) & Mexico & 2011 & $14.40 \%$ & - & (61) & Mexico & 2011 & $11.60 \%$ & - \\
\hline (4) & Pakistan & 2010 & $0.20 \%$ & - & (62) & Russia & 2011 & $10.4 \%$ & - \\
\hline (6) & Turkey & 2010 & $18.40 \%$ & - & (63) & Brazil & 2011 & $55.30 \%$ & - \\
\hline (8) & Spain & 2009 & $3 \%$ & - & (64) & Venezuela & 2007 & $64 \%$ & - \\
\hline (10) & Spain & 2008 & $32.10 \%$ & - & (65) & Brazil & 2011 & $36.10 \%$ & - \\
\hline (12) & Turkey & 2008 & 22.5 & - & (66) & Russia & 2006 & $44.8 \%$ & - \\
\hline (14) & Germany & 2007 & $5.8 \%$ & - & (67) & South Africa & 2011 & $33 \%$ & - \\
\hline (16) & South Africa & 2006 & $29.20 \%$ & Yes & (68) & China & 2011 & $3.6 \%$ & Yes \\
\hline
\end{tabular}

Table 2. Pooled sensitivity (CI: 95\%) and heterogeneity for M. tuberculosis LAM family in worldwide population based on year.

\begin{tabular}{|c|c|c|c|c|}
\hline Stratum & Proportion & $95 \% \mathrm{CI}$ & $\%$ Weights (fixed, random) & Year \\
\hline 1 & 0.29 & $0.24 ; 0.34$ & $1.53 ; 9.80$ & 2000 \\
\hline 2 & 0.31 & $0.28 ; 0.35$ & $3.05 ; 10.05$ & 2004 \\
\hline 3 & 0.05 & $0.03 ; 0.07$ & $2.81 ; 10.03$ & 2005 \\
\hline 4 & 0.44 & $0.42 ; 0.45$ & $14.55 ; 10.26$ & 2006 \\
\hline 5 & 0.44 & $0.21 ; 0.23$ & $18.32 ; 10.27$ & 2007 \\
\hline 6 & 0.16 & $0.13 ; 0.19$ & $3.40 ; 10.08$ & 2008 \\
\hline 7 & 0.25 & $0.23 ; 0.26$ & $15.84 ; 10.27$ & 2009 \\
\hline 8 & 0.23 & $0.22 ; 0.24$ & $22.35 ; 10.28$ & 2010 \\
\hline 9 & 0.16 & $0.15 ; 0.17$ & $17.68 ; 10.27$ & 2011 \\
\hline 10 & 0.05 & $0.01 ; 0.11$ & $0.41 ; 8.64$ & 2012 \\
\hline
\end{tabular}

MDR-TB: MDR -TB prevalence analysis showed positive MDR between $M$. tuberculosis LAM family $(95 \%$ CI: $10.30 \%-11.23 \%)$. Prevalence for negative MDR was $9.22 \%$ (95\% CI: $8.3 \%-10.2 \%)$.
In this heterogeneity, $\mathrm{I}^{2}=79.4$, Chi squared $=9.69, \mathrm{df}=2$ with $\mathrm{P}<0.00$, tau squared $=$ 0.00 with $\mathrm{P}=0.00$ were observed. Also, no publication bias was observed. 


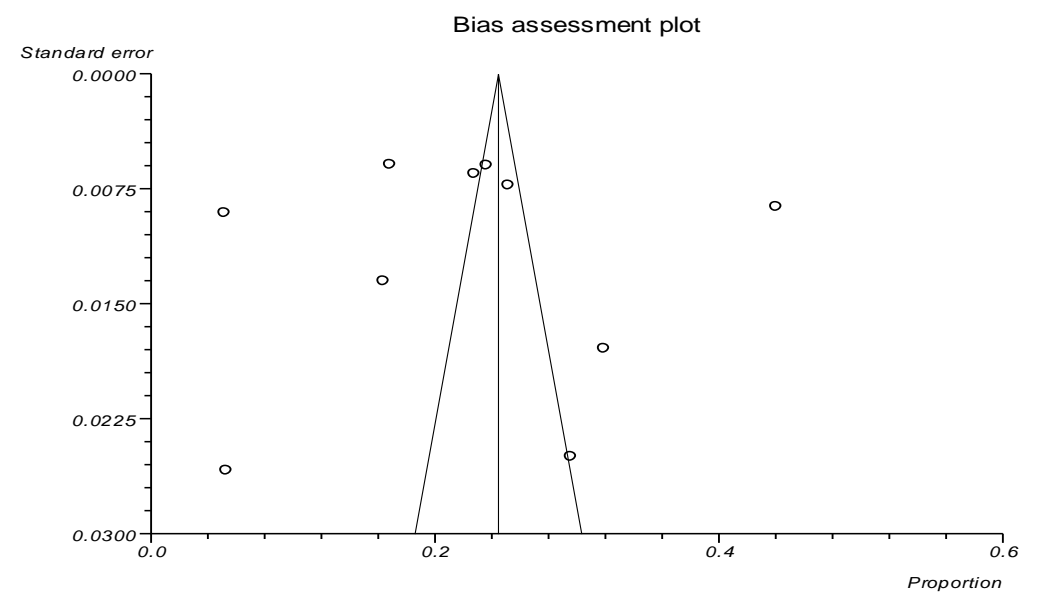

Figure 1. Results of publication bias for M. tuberculosis LAM family in worldwide population based on year (CI: $95 \%)$.

\section{Discussion}

Studies proved that MDR in patients with TB is related with high mortality (1). In this study we survey prevalence and occurrence rate of MDR-M. tuberculosis LAM family during 10 years between world population according to a systematic review and metaanalysis. Results in this study showed that lowest and highest rates of $M$. tuberculosis LAM family prevalence were in $2010(0.2$ $\%)$ and $2006(0.2 \%)$, and $2006(74 \%)$, respectively. Also a transmission of this family was observed in our study during 10 years among 36 countries. Dye et al. in 2009 in Switzerland reported that estimated global TB incidence was $63 \%$ during $1997-$ 2006 between 211 countries (68). Different factors can affect TB occurrence rate in countries. These factors including poor living conditions, cigarette smoking, diabetes, chronic peritoneal dialysis, MDRTB, imprisonment, HIV infection, alcohol abuse, and air pollution (69).Jagielski et al. in 2009 in France reported that MDR strains (13\%) were detected in 27 patients with TB (70). Also Durmaz et al. in Turkey in 2007 showed MDR in clinical isolates of $M$. tuberculosis of $\mathrm{T}$ super-family (29\%), LAM (33.5\%), Haarlem (14\%), and S lineage $(3 \%)$ (71). MDR positive in different countries in our study was observed. Also negative MDR was 9.22\%. Different factors such as spread of MDRTB strains, acquired resistance during resistance gene transmission in patients and geographical distribution among neighboring countries are important factors for MDR-TB different rates in studies. Also genetic variation is related to prevalence and spread of drug-resistant strains. So genotyping is an important tool for detection of origin and transmission patterns of drug-resistant strains (72). There are several methods for molecular typing of M. tuberculosis such as: Spoligotyping, RFLP typing based on the IS6110 and VNTR (6 -8). Spoligotyping is a major technical for molecular typing of $M$. tuberculosis (70). This typing method is based on DNA presence of polymorphism at one particular chromosomal locus, the "Direct Repeat" (DR) region, which is in $M$. tuberculosis complex bacteria (7). The DR locus consists of conserved direct repeatations interspersed with unique spacer sequences (8). Therefore we study LAM family prevalence and occurrence rate by spoligotyping method. Association between LAM family and MDR in articles that obtained in different countries was observed. In a study in 2014 in Iraq, Ahmed et al. with spoligotyping yielded 39 patterns among 270 isolates from 134 patients. In Ahmed's study, 70 isolates were found as MDR (73). Imperiale et al. in 2013 in Argentina by spoligotyping showed that Haarlem, LAM and T family were the main 
spoligotyping families and katG315 gene mutation was mainly associated with LAM family (74). Resistance to drugs in $M$. tuberculosis families may be associated with MDR and different among various families (69). In our meta-analysis different original article obtained from PubMed, Science Direct, Google Scholar, Biological Abstracts, and ISI web of knowledge in Thomson Reuters with regard to prevalence of LAM family in world population. In this review, we use statistical analysis and proved association drug resistance in total published reports. MDR -M. tuberculosis families can be found in different countries, so an outbreak of MDR-TB in populations

\section{References}

1. Glickman MS, Jacobs WR Jr. Microbial pathogenesis of Mycobacterium tuberculosis: dawn of a discipline. Cell. 2001;104(4):477-85.

2. Brosch R, Gordon SV, Pym A, Eiglmeier K, Garnier T, Cole ST. Comparative genomics of the mycobacteria. Int $\mathrm{J}$ Med Microbiol. 2000;290(2):143-52.

3. Smith I. Mycobacterium tuberculosis pathogenesis and molecular determinants of virulence. Clin Microbiol Revi. 2003;16(3):463-96.

4. Bryant JM, Schurch AC, van Deutekom $\mathrm{H}$, Harris SR, de Beer JL, de Jager V, et al. Inferring patient to patient transmission of Mycobacterium tuberculosis from whole genome sequencing data. BMC Infect Dis. 2013 (2013);13:110.

5. Afanas'ev MV, Ikryannikova LN, Il'ina EN, Kuz'min AV, Larionova EE, Smirnova TG, et al. Molecular typing of Mycobacterium tuberculosis circulated in Moscow, Russian Federation. Eur J Clin Microbiol Infect Dis. 2011;30(2):18191.

6. Roetzer A, Schuback S, Diel R, Gasau $F$, Ubben $T$, di Nauta $A$, et al. Evaluation of Mycobacterium can be occurred. A program for detection and prevention of MDR-M. tuberculosis family's transmission is necessary $(69,75)$. It is hoped this systematic review and metaanalysis can be effective on control, prevention of transmission, origin detection of LAM Family and its control.

\section{Acknowledgements}

This is a part of our project. The authors wish to extend their gratitude to the Research Deputy of Kurdistan University of Medical Sciences for financial support. The authors declare that there is no conflict of interest.

tuberculosis typing methods in a 4-year study in Schleswig-Holstein, Northern Germany. J Clin Microbiol. 2011;49(12):4173-8.

7. Brudey K, Driscoll JR, Rigouts L, Prodinger WM, Gori A, Al-Hajoj SA, et al. Mycobacterium tuberculosis complex genetic diversity: mining the fourth international spoligotyping database (SpolDB4) for classification, population genetics and epidemiology. BMC Microbiol. 2006 (2006);6:23.

8. Vitol I, Driscoll J, Kreiswirth B, Kurepina N, Bennett KP. Identifying Mycobacterium tuberculosis complex strain families using spoligotypes. Infect Genet Evol. 2006;6(6):491-504.

9. Homolka S, Projahn M, Feuerriegel S, Ubben T, Diel R, Nubel U, et al. High resolution discrimination of clinical Mycobacterium tuberculosis complex strains based on single nucleotide polymorphisms. PLoS One. 2012;7(7):e39855.

10. Liao YC, Chen YY, Lin HH, Chang JR, $\mathrm{Su}$ IJ, Huang TS, et al. Draft Genome Sequence of the Mycobacterium tuberculosis clinical isolate $\mathrm{C} 2$, belonging to the latin americanmediterranean family. Genome Announc. 2014;2(3): e00536-14. 
11. Mokrousov I, Vyazovaya A, Narvskaya O. Mycobacterium tuberculosis Latin American-Mediterranean family and its sublineages in the light of robust evolutionary markers. J Bacteriol. 2014;196(10):1833-41.

12. Almeida Da Silva PE, Palomino JC. Molecular basis and mechanisms of drug resistance in Mycobacterium tuberculosis: classical and new drugs. J Antimicrob Chemother. 2011;66(7):1417-30.

13. Ackart DF, Lindsey EA, Podell BK, Melander RJ, Basaraba RJ, Melander C. Reversal of Mycobacterium tuberculosis phenotypic drug resistance by 2-aminoimidazole-based small molecules. Pathog Dis. 2014;70(3):370-8.

14. Engstrom A, Morcillo N, Imperiale B, Hoffner SE, Jureen P. Detection of firstand second-line drug resistance in Mycobacterium tuberculosis clinical isolates by pyrosequencing. J Clin Microbiol. 2012;50(6):2026-33.

15. Araya P, Velasco M, Tognarelli J, Arias F, Leiva T, Sccapatticio A, et al. Detection of genes associated with drug resistance in Mycobacterium tuberculosis strains isolated in Chile. Rev Med Chil. 2011;139(4):467-73.

16. Tracevska T, Jansone I, Broka L, Marga $\mathrm{O}$, Baumanis V. Mutations in the rpoB and katG genes leading to drug resistance in Mycobacterium tuberculosis in Latvia. J Clin Microbiol. 2002;40(10):3789-92.

17. Ignatova A, Dubiley S, Stepanshina V, Shemyakin I. Predominance of multidrug-resistant LAM and Beijing family strains among Mycobacterium tuberculosis isolates recovered from prison inmates in Tula Region, Russia. J Med Microbiol. 2006; 55(Pt 10): 1413-18.

18. Valcheva V, Rastogi N, Mokrousov I. Prevalence of Latin-AmericanMediterranean genetic family in population structure of Mycobacterium tuberculosis in Bulgaria. Int $\mathbf{J}$ Mycobacteriol. 2015; 11;4(3):191-5.

19. Dymova MA, Liashenko OO, Poteiko PI, Krutko VS, Khrapov EA, Filipenko ML. Genetic variation of Mycobacterium tuberculosis circulating in Kharkiv Oblast, Ukraine. BMC Infect Dis. 2011;11(77):3-10.

20. Niemann S, Diel R, Khechinashvili G, Gegia M, Mdivani N, Tang YW. Mycobacterium tuberculosis Beijing lineage favors the spread of multidrugresistant tuberculosis in the republic of Georgia. J Clin Microbiol. 2010;48(10):3544-50.

21. Yeboah-Manu D, Asante-Poku A, Bodmer T, Stucki D, Koram K, Bonsu F, et al. Genotypic diversity and drug susceptibility patterns among $\mathrm{M}$. tuberculosis complex isolates from South-Western Ghana. PLoS One. 2011;6(7):e21906.

22. Groenheit R, Ghebremichael S, Svensson J, Rabna P, Colombatti R, Riccardi F, et al. The Guinea-Bissau family of Mycobacterium tuberculosis complex revisited. PLoS One. 2011;6(4):e18601.

23. Gomes HM, Elias AR, Oelemann MA, Pereira MA, Montes FF, Marsico AG, et al. Spoligotypes of Mycobacterium tuberculosis complex isolates from patients residents of 11 states of Brazil. Infect Genet Evol. 2012;12(4):649-56.

24. Ferro BE, Nieto LM, Rozo JC, Forero L, van Soolingen D. Multidrug-resistant Mycobacterium tuberculosis, Southwestern Colombia. Emerg Infect Dis. 2011;17(7):1259-62.

25. Viegas SO, Machado A, Groenheit R, Ghebremichael S, Pennhag A, Gudo PS, et al. Molecular diversity of Mycobacterium tuberculosis isolates from patients with pulmonary tuberculosis in Mozambique. BMC Microbiol. 2010; 21(10):195.

26. Rosales S, Pineda-Garcia L, Ghebremichael S, Rastogi N, Hoffner S. Molecular diversity of Mycobacterium tuberculosis isolates 
from patients with tuberculosis in Honduras. BMC Microbiol. 2010; 3(10):208.

27. Ojo O, Sheehan S, Corcoran D, Nikolayevsky V, Brown T, O'Sullivan $\mathrm{M}$, et al. Molecular epidemiology of Mycobacterium tuberculosis clinical isolates in Southwest Ireland. Infect Genet Evol. 2010;10(7):1110-6.

28. Mallard K, McNerney R, Crampin AC, Houben R, Ndlovu R, Munthali L, et al. Molecular detection of mixed infections of Mycobacterium tuberculosis strains in sputum samples from patients in Karonga District, Malawi. J Clin Microbiol. 2010;48(12):4512-8.

29. Lai CC, Tan CK, Lin SH, Liao CH, Huang YT, Chou CH, et al. Clinical and genotypic characteristics of extensively drug-resistant and multidrug-resistant tuberculosis. Eur J Clin Microbiol Infect Dis. 2010;29(5):597-600.

30. Jagielski T, Augustynowicz-Kopec E, Zozio T, Rastogi N, Zwolska Z. Spoligotype-based comparative population structure analysis of multidrug-resistant and isoniazidmonoresistant Mycobacterium tuberculosis complex clinical isolates in Poland. J Clin Microbiol. 2010;48(11):3899-909.

31. Hu Y, Hoffner S, Jiang W, Wang W, Xu B. Extensive transmission of isoniazid resistant $M$. tuberculosis and its association with increased multidrugresistant $\mathrm{TB}$ in two rural counties of eastern China: a molecular epidemiological study. BMC Infect Dis. 2010; 2010 (10):43.

32. Hesseling AC, Marais BJ, Kirchner HL, Mandalakas AM, Brittle W, Victor TC, et al. Mycobacterial genotype is associated with disease phenotype in children. Int $\mathbf{J}$ Tuberc Lung Dis. 2010;14(10):1252-8.

33. Garzelli C, Lari N, Cuccu B, Tortoli E, Rindi L. Impact of immigration on tuberculosis in a low-incidence area of Italy: a molecular epidemiological approach. Clin Microbiol Infect. 2010;16(11):1691-7.

34. Mokrousov I, Otten T, Zozio T, Turkin E, Nazemtseva V, Sheremet A, et al. At Baltic crossroads: a molecular snapshot of Mycobacterium tuberculosis population diversity in Kaliningrad, Russia. FEMS Immunol Med Microbiol. 2009;55(1):13-22.

35. Abadia E, Sequera M, Ortega D, Mendez M, Escalona A, Da Mata O, et al. Mycobacterium tuberculosis ecology in Venezuela: epidemiologic correlates of common spoligotypes and a large clonal cluster defined by MIRUVNTR-24. BMC Infect Dis. 2009; 9 (2009): 122.

36. Valcheva V, Mokrousov I, Narvskaya O, Rastogi N, Markova N. Utility of new 24-locus variable-number tandemrepeat typing for discriminating Mycobacterium tuberculosis clinical isolates collected in Bulgaria. J Clin Microbiol. 2008;46(9):3005-11.

37. Homolka S, Post E, Oberhauser B, George AG, Westman L, Dafae F, et al. High genetic diversity among Mycobacterium tuberculosis complex strains from Sierra Leone. BMC Microbiol. 2008;8 (2008):103.

38. Lipin M, Stepanshina V, Shemyakin I, Shinnick T. Association of specific mutations in katG, rpoB, rpsL and rrs genes with spoligotypes of multidrugresistant Mycobacterium tuberculosis isolates in Russia. Clin Microbiol Infect. 2007;13(6):620-6.

39. Lari N, Rindi L, Bonanni D, Rastogi N, Sola C, Tortoli E, et al. Three-year longitudinal study of genotypes of Mycobacterium tuberculosis isolates in Tuscany, Italy. J Clin Microbiol. 2007;45(6):1851-7.

40. Kisa O, Albay A, Baylan O, Tozkoparan E, Acikel C, Doganci L. Genetic diversity of Mycobacterium tuberculosis isolates at the Military Medical Academy in Ankara, Turkey. Res Microbiol. 2007;158(4):318-23. 
41. Durmaz R, Zozio T, Gunal S, Yaman A, Cavusoglu C, Guney C, et al. Genetic diversity and major spoligotype families of drug-resistant Mycobacterium tuberculosis clinical isolates from different regions of Turkey. Infect Genet Evol. 2007;7(4):513-9.

42. Candia N, Lopez B, Zozio T, Carrivale M, Diaz C, Russomando G, et al. First insight into Mycobacterium tuberculosis genetic diversity in Paraguay. BMC Microbiol. 2007;7 (2007):75.

43. Al-Hajoj SA, Zozio T, Al-Rabiah F, Mohammad V, Al-Nasser M, Sola C, et al. First insight into the population structure of Mycobacterium tuberculosis in Saudi Arabia. J Clin Microbiol. 2007;45(8):2467-73.

44. Aristimuno L, Armengol R, Cebollada A, Espana M, Guilarte A, Lafoz C, et al. Molecular characterisation of Mycobacterium tuberculosis isolates in the First National Survey of Antituberculosis Drug Resistance from Venezuela. BMC Microbiol. 2006;6 (2006):90.

45. Lari N, Rindi L, Sola C, Bonanni D, Rastogi N, Tortoli E, et al. Genetic diversity, determined on the basis of katG463 and gyrA95 polymorphisms, Spoligotyping, and IS6110 typing, of Mycobacterium tuberculosis complex isolates from Italy. J Clin Microbiol. 2005;43(4):1617-24.

46. Shemyakin IG, Stepanshina VN, Ivanov IY, Lipin MY, Anisimova VA, Onasenko AG, et al. Characterization of drug-resistant isolates of Mycobacterium tuberculosis derived from Russian inmates. Int $\mathrm{J}$ Tuberc Lung Dis. 2004;8(10):1194-203.

47. Ivanov II, Stepanshina V, Lipin MI, Korobova O, Shemiakin I. Spoligotypes of clinical Mycobacterium tuberculosis strains isolated in patients with tuberculosis in the Central Region of Russia. Probl Tuberk Bolezn Legk. 2004;(4):23-7.
48. Vasankari T, Soini H, Liippo K, Ruutu P. MDR-TB in Finland--still rare despite the situation in our neighbouring countries. Clin Respir J. 2012;6(1):35-9.

49. Sharaf Eldin GS, Fadl-Elmula I, Ali MS, Ali AB, Salih AL, Mallard K, et al. Tuberculosis in Sudan: a study of Mycobacterium tuberculosis strain genotype and susceptibility to antituberculosis drugs. BMC Infect Dis. 2011;11 (2011):219.

50. Nava-Aguilera E, Lopez-Vidal Y, Harris E, Morales-Perez A, Mitchell S, Flores-Moreno M, et al. Clustering of Mycobacterium tuberculosis cases in Acapulco: Spoligotyping and risk factors. Clin Dev Immunol. 2011;2011 (2011):408375.

51. Miranda SS, Carvalho Wda S, Suffys PN, Kritski AL, Oliveira M, Zarate N, et al. Spoligotyping of clinical Mycobacterium tuberculosis isolates from the state of Minas Gerais, Brazil. Mem Inst Oswaldo Cruz. 2011;106(3):267-73.

52. Mendes NH, Melo FA, Santos AC, Pandolfi JR, Almeida EA, Cardoso RF, et al. Characterization of the genetic diversity of Mycobacterium tuberculosis in Sao Paulo city, Brazil. BMC Res Notes. 2011;4 (2011):269.

53. Cohen T, Wilson D, Wallengren $\mathrm{K}$, Samuel EY, Murray M. Mixed-strain Mycobacterium tuberculosis infections among patients dying in a hospital in KwaZulu-Natal, South Africa. J Clin Microbiol. 2011;49(1):385-8.

54. Molina-Torres CA, Moreno-Torres E, Ocampo-Candiani J, Rendon A, Blackwood K, Kremer K, et al. Mycobacterium tuberculosis spoligotypes in Monterrey, Mexico. J Clin Microbiol. 2010;48(2):448-55.

55. Merza MA, Farnia P, Salih AM, Masjedi MR, Velayati AA. The most predominant spoligopatterns of Mycobacterium tuberculosis isolates among Iranian, Afghan-immigrant, Pakistani and Turkish tuberculosis 
patients: a comparative analysis. Chemotherapy. 2010;56(3):248-57.

56. Merza MA, Farnia P, Salih AM, Masjedi MR, Velayati AA. First insight into the drug resistance pattern of Mycobacterium tuberculosis in Dohuk, Iraq: using spoligotyping and MIRUVNTR to characterize multidrug resistant strains. J Infect Public Health. 2011;4(1):41-7.

57. Lopez-Calleja AI, Gavin P, Lezcano MA, Vitoria MA, Iglesias MJ, Guimbao $\mathrm{J}$, et al. Unsuspected and extensive transmission of a drug-susceptible Mycobacterium tuberculosis strain. BMC Pulm Med. 2009;9 (2009):3.

58. Alonso-Rodriguez N, Martinez-Lirola M, Herranz M, Sanchez-Benitez M, Barroso P, Bouza E, et al. Evaluation of the new advanced 15-loci MIRUVNTR genotyping tool in Mycobacterium tuberculosis molecular epidemiology studies. BMC Microbiol. 2008;8 (2008): 34.

59. Aktas E, Zozio T, Comert FB, Kulah C, Aydin O, Rastogi N, et al. A first insight into the genetic diversity and population structure of Mycobacterium tuberculosis in Zonguldak, Turkey. Clin Microbiol Infect. 2008;14(1):55-9.

60. Oelemann MC, Diel R, Vatin V, Haas $\mathrm{W}$, Rusch-Gerdes S, Locht $\mathrm{C}$, et al. Assessment of an optimized mycobacterial interspersed repetitiveunit-variable-number tandem-repeat typing system combined with spoligotyping for population-based molecular epidemiology studies of tuberculosis. J Clin Microbiol. 2007;45(3):691-7.

61. Marais BJ, Victor TC, Hesseling AC, Barnard M, Jordaan A, Brittle W, et al. Beijing and Haarlem genotypes are overrepresented among children with drug-resistant tuberculosis in the Western Cape Province of South Africa. J Clin Microbiol. 2006;44(10):3539-43.

62. Eldholm V, Matee M, Mfinanga SG, Heun M, Dahle UR. A first insight into the genetic diversity of Mycobacterium tuberculosis in Dar es Salaam, Tanzania, assessed by spoligotyping. BMC Microbiol. 2006;6 (2006):76.

63. Brudey K, Filliol I, Ferdinand S, Guernier V, Duval P, Maubert B, et al. Long-term population-based genotyping study of Mycobacterium tuberculosis complex isolates in the French departments of the Americas. J Clin Microbiol. 2006;44(1):183-91.

64. Ramazanzadeh R, Amirmozafari N, Farnia P, Ghazi F. Genotyping of Mycobacterium Tuberculosis isolates from TB patients with spoligotyping. SJKUMS. 2006;11(39):50-9.

65. van Crevel R, Parwati I, Sahiratmadja E, Marzuki S, Ottenhoff TH, Netea $\mathrm{MG}$, et al. Infection with Mycobacterium tuberculosis Beijing genotype strains is associated with polymorphisms in SLC11A1/NRAMP1 in Indonesian patients with tuberculosis. J Infect Dis. 2009;200(11):1671-4.

66. Phyu S, Stavrum R, Lwin T, Svendsen OS, Ti T, Grewal HM. Predominance of Mycobacterium tuberculosis EAI and Beijing lineages in Yangon, Myanmar. J Clin Microbiol. 2009;47(2):335-44.

67. Otlu B, Durmaz R, Gunal S, Sola C, Zozio T, Rastogi N. Beijing/W and major spoligotype families of Mycobacterium tuberculosis strains isolated from tuberculosis patients in Eastern Turkey. New Microbiol. 2009;32(3):255-63.

68. Dye C, Lönnroth K, Jaramillo E, Williams BG, Raviglione M. Trends in tuberculosis incidence and their determinants in 134 countries. Bull World Health Organ. 2013; 17(8): 1088-93.

69. RamazanzadehR, RoshaniD, ShakibP, RouhiS. Prevalence and occurrence rate of Mycobacterium tuberculosis Haarlem family multi-drug resistant in the worldwide population: A systematic review and meta-analysis. J Res Med Sci. 2015;20 (1): 78-88. 
70. Jagielski T, Augustynowicz-Kopec' E, Zozio T, Rastogi N, Zofia Zwolska Z. Spoligotype-based comparative population structure analysis of multidrug-resistant and isoniazidmonoresistant Mycobacterium tuberculosis complex clinical isolates in Poland. J Clin Microbiol. 2010; 48 (11): 3899-909.

71. Durmaz R, Zozio T, Gunal S, Yaman A, Cavusoglu C, Guney C, et al. Genetic diversity and major spoligotype families of drug-resistant Mycobacterium tuberculosis clinical isolates from different regions of Turkey. Infect Genet Evol. 2007;7 (4):513-9.

72. Marais BJ, Victor TC, Hesseling AC, Barnard M, Jordaan A, Brittle W, et al. Beijing and Haarlem genotypes are overrepresented among children with drug-resistant tuberculosis in the Western Cape Province of South Africa. J Clin Microbiol. 2006; 44 (10): 3539-43.
73. Ahmed MM, Mohammed SH, Abood Nasurallah HA, Ali MM, Couvin D, Rastogi N. Snapshot of the genetic diversity of Mycobacterium tuberculosis isolates in Iraq. Int $\mathbf{J}$ Mycobacteriol. 2014; 3(3):184-96.

74. Imperiale BR, Zumárraga MJ, Di Giulio AB, Cataldi AA, Morcillo NS. Molecular and phenotypic characterisation of Mycobacterium tuberculosis resistant to antituberculosis drugs. Int $\mathbf{J}$ Tuberc Lung Dis. 2013;17(8):1088-93.

75. Aranaz A, Romero B, Montero N, Alvarez J, Bezos J, de Juan L, et al. Spoligotyping profile change caused by deletion of a direct variable repeat in a Mycobacterium tuberculosis isogenic laboratory strain. J Clin Microbiol. 2004;42(11):5388-91. 